\title{
ARTÍ́CULO
}

\section{Reproducción de la cabrilla pinta Epinephelus labriformis en la Bahía de Navidad, Jalisco, México}

Reproduction of the flag cabrilla Epinephelus labriformis in the Bahía de Navidad, Jalisco, Mexico

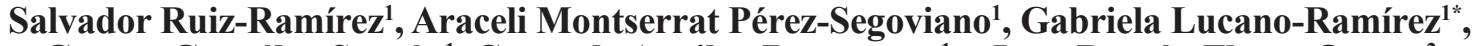 Gaspar González-Sansón ${ }^{1}$, Consuelo Aguilar-Betancourt ${ }^{1}$ y Juan Ramón Flores-Ortega ${ }^{2}$}

\begin{abstract}
'Departamento de Estudios para el Desarrollo Sustentable de Zonas Costeras, Universidad de Guadalajara, Gómez Farías 82, San Patricio-Melaque, Cihuatlán, Jalisco, CP 48980, México. *Autor corresponsal: lucanog19@gmail.com ${ }^{2}$ Escuela Nacional de Ingeniería Pesquera, Universidad Autónoma de Nayarit, Apartado postal No 10, Bahía de Matanchén Km 12, San Blas, Nayarit, México, CP 63740
\end{abstract}

\begin{abstract}
The flag cabrilla, Epinephelus labriformis, is a species of the Serranidae family exploited by commercial fisheries in the Bahía de Navidad, Jalisco, Mexico. The goal of this research was to describe the reproductive characteristics of $E$. labriformis. Monthly samples were taken from 1998 to 2008 using gillnets. Total length (TL) and total weight (TW) were recorded for each sampled specimen. Gonads were collected, weighted, classified according to their maturation stage and preserved for histological analyses. A total of 940 fish were collected, 521 females and 419 males. Mean length was $30.1( \pm 0.14) \mathrm{cm}$ TL for females and $31.3( \pm 0.13) \mathrm{cm}$ TL for males. The highest values of the gonadosomatic index and percentage of ripe gonads in both males and females were found in April and August. Condition factor showed little temporal variation. Transitional individuals were identified based on gonad histology; they had ovaries with oocytes in regression and developing testicular tissue. Oocyte development was asynchronical and testicles were lobular. The smallest transition fish was $25.6 \mathrm{~cm}$ TL. Mean sexual maturation length was $29.6 \mathrm{~cm}$ for females and $31.3 \mathrm{~cm}$ for males. Based on maturation lengths and on the length composition of commercial catches, we can assume that caught fish have had, at least, one reproductive event. Main reproductive activity in E. labriformis occurs in spring and summer. Protogynous hermaphroditism was confirmed for this species; this characteristic makes it more vulnerable to fishing impact.
\end{abstract}

Key words: Reproductive cycle, Serranidae, protogynous, maturation length, gonadosomatic index

\begin{abstract}
Resumen.- La cabrilla pinta, Epinephelus labriformis, es una especie de la familia Serranidae, explotada comercialmente en la Bahía de Navidad, Jalisco, México. El objetivo del trabajo fue describir las características reproductivas de E. labriformis. Se realizaron muestreos mensuales entre 1998 y 2008 utilizando redes agalleras. De cada organismo se obtuvo la longitud total (LT) y el peso total (PT); las gónadas fueron extraídas, pesadas, clasificadas según el estadio de desarrollo y preservadas para análisis histológicos. Se recolectaron 940 ejemplares, 521 fueron hembras y 419 machos. La longitud promedio de las hembras fue de $30,1( \pm 0,14) \mathrm{cm}$ y la de los machos 31,3 $( \pm 0,13) \mathrm{cm}$ LT. Los máximos valores del índice gonadosomático y los mayores porcentajes de gónadas maduras tanto en hembras como en machos, se presentaron en abril y agosto. El factor de condición presentó escasa variación temporal. Mediante el análisis histológico de las gónadas se identificaron ejemplares en transición, con ovarios con ovocitos en regresión y tejido testicular en desarrollo. El desarrollo de los ovocitos es asincrónico y el del testículo es de tipo lobular. El ejemplar más pequeño encontrado en transición midió 25,6 cm LT. La longitud promedio de maduración sexual fue 29,6 cm LT para hembras y 31,3 cm LT para machos; contrastando estas tallas con las de captura, se infiere que los individuos capturados habrían tenido al menos un evento reproductivo. E. labriformis es un hermafrodita protógino que presenta una mayor actividad reproductiva en primavera-verano lo cual lo vuelve altamente vulnerable al impacto de la pesca.
\end{abstract}

Palabras clave: Ciclo reproductivo, Serranidae, protógino, talla de madurez, índice gonadosomático

\section{INTRODUCCIÓN}

La familia Serranidae incluye 449 especies cosmopolitas que se distribuyen en hábitats costeros y constituyen uno de los mayores grupos de peces en arrecifes rocosos y coralinos (Heemstra \& Randall 1993, Aburto-Oropeza et al. 2008). Las especies de esta familia tienen importancia comercial y son explotadas por pesquerías artesanales, recreativas e industriales; varias especies son cotizadas en el mercado de la acuariofilia (Aburto-Oropeza et al. 2008).

Epinephelus labriformis (Jenyns, 1840) es una especie de talla mediana alcanza los $52 \mathrm{~cm} \mathrm{LT} \mathrm{(Craig} \mathrm{et} \mathrm{al.} \mathrm{2011)}$ que se distingue de otras del mismo género por su patrón de coloración; se distribuye en el Pacífico oriental, desde la isla de Cedros, México, hasta Perú, incluyendo las islas Cocos, Revillagigedo y las Galápagos, donde habita en arrecifes poco profundos, aunque los adultos se encuentran a $30 \mathrm{~m}$ de profundidad (Heemstra \& Randall 1993). Esta especie se considera de importancia para las pesquerías artesanales locales y se captura mediante línea, anzuelo, trampas y redes de enmalle (Gotshall 1998).

Son escasos los trabajos que se han realizado sobre $E$. labriformis; entre estos, en el Pacífico central mexicano la especie sólo aparece en listados faunísticos en Jalisco y Colima (Aguilar-Palomino et al. 2001, Lucano-Ramírez et al. 2001a, Rojo-Vázquez et al. 2001, 2008). RodríguezIbarra (1995) realizó un estudio sobre ictiofauna de la Bahía 
de Navidad, Jalisco y determinó que la familia Serranidae era la mayor representada, con 11 especies (incluyendo a E. labriformis). Rojo-Vázquez \& Ramírez-Rodríguez (1997) analizaron la selectividad y eficiencia de redes de enmalle en la misma bahía. Estos autores reportaron que de las 75 especies registradas, E. labriformis fue una de las 7 más abundantes. Cruz-Romero et al. (1987) y Craig et al. (1999) estudiaron la edad y el crecimiento de E. labriformis en Colima, y Bahía de Banderas, Jalisco e Islas Galápagos, respectivamente. En tanto, Erisman (2008) señaló que $E$. labriformis es una especie hermafrodita protógina y observó mayor actividad reproductiva en enero y de abril a octubre en México. La información científica disponible acerca de la biología y la ecología de E. labriformis es escasa. Es una especie que se captura durante todo el año, y es el serránido que más se pesca en la región, y se ubica entre las 10 especies con mayor abundancia (Rojo-Vázquez et al. 2001, 2008). Además, presenta un patrón reproductivo peculiar, por lo que la intensa actividad pesquera podría tener gran impacto en sus poblaciones. El objetivo de este trabajo fue describir algunos aspectos reproductivos de la cabrilla pinta E. labriformis en la Bahía de Navidad, Jalisco, México, para un manejo sustentable de la pesquería de la especie.

\section{MATERIALES Y MÉTODOS}

La Bahía de Navidad se localiza en la costa sur de Jalisco y norte de Colima (19¹1'25’N-104³9'53”O), en el Pacífico central de México. En esta zona, se realizaron muestreos mensuales durante 5 días consecutivos entre enero 1998 y diciembre 2008. Los peces provinieron de la captura comercial realizada con redes agalleras de diferente luz de malla, las cuales operaron en promedio durante $12 \mathrm{~h}$. A los individuos capturados de Epinephelus labriformis se les registró la longitud total (LT) $( \pm 0,1 \mathrm{~cm})$ y el peso total (PT) $( \pm 0,1 \mathrm{~g})$. Se extrajeron las gónadas, se obtuvo su peso $(\mathrm{Pg})( \pm 0,01 \mathrm{~g})$, se identificó el sexo mediante observación directa, se les asignó un estado de maduración según Everson et al. (1989) en una escala de 4 estadios (inmaduro, en desarrollo, maduro y desovado) y se fijaron en formol neutro al $10 \%$ para su posterior análisis histológico. Para ello las gónadas se deshidrataron con alcohol etílico y se incluyeron en paraplast; se obtuvieron cortes de 6-8 $\mu \mathrm{m}$ y se usó tinción con hematoxilina-eosina. Para cada estadio de maduración se obtuvo el área $\left(\mathrm{A}, \mathrm{mm}^{2}\right)$ de la parte media de la gónada. Las diferentes fases de ovocitos se clasificaron de acuerdo con Yamamoto \& Yamazaki (1961), LucanoRamírez et al. (2001b) y Brown-Peterson et al. (2011). Se obtuvo el diámetro (DO) de 10 ovocitos (West 1990) de cada una de las fases identificadas en cada estadio de maduración $(\mathrm{n}=91)$. También se obtuvieron porcentajes de cada fase de ovocito presentes en cada uno de los 4 estadios de maduración del ovario. Para la descripción interna del testículo $(\mathrm{N}=200)$ se tomaron en cuenta los trabajos de Hyder (1969), Lucano-Ramírez et al. (2001c) y BrownPeterson et al. (2011).
La proporción sexual se obtuvo como la razón entre el número de hembras y el número de machos, y se calculó para la muestra total, por mes y por clase de longitud. Para comparar las proporciones entre sexos se utilizó la prueba Chi-cuadrado $\left(\chi^{2}\right)$ (Zar 2010).

Para definir la duración de la temporada reproductiva se aplicaron 3 métodos. En el primero se evaluaron los porcentajes mensuales de peces con gónadas maduras. El segundo incluyó el cálculo del índice gonadosomático: $I G S=[\mathrm{Pg} /(\mathrm{PT}-\mathrm{Pg})] \times 100$; el cual se ha empleado como indicador del periodo reproductivo, bajo el supuesto de que los valores promedio máximos indican madurez gonádica (Sánchez-Cárdenas et al. 2007). El tercer método consistió en analizar la variación mensual del diámetro promedio de los ovocitos, considerando que un mayor diámetro promedio del ovocito corresponde a un mayor grado de maduración del ovario.

Se calculó el factor de condición relativo: $F C r=(\mathrm{PT} /$ $\left.\mathrm{LT}^{b}\right)$ x 100; donde $b$ es la constante de la regresión potencial longitud-peso, basándose en que los peces de mayor peso de una misma longitud presentan una mejor condición corporal (Froese 2006). Se calculó la talla de madurez sexual $\left(\mathrm{L}_{50}\right)$, definida como la longitud en la que el 50\% de los individuos se encuentran maduros sexualmente. Para su cálculo se utilizó la ecuación $P_{L T}=1 /\left[1+\mathrm{e}^{\left(b^{*} \mathrm{LT}+a\right)}\right] \times 100$, en la cual $P_{L T}$ es la fracción de peces maduros, esto es, los individuos que presentaron gónadas en los estadios en desarrollo, maduros y desovados (Everson et al. 1989) para cada clase de longitud total (LT), las constantes $b$ y $a$ (regresión logarítmica) de la ecuación anterior se ajustaron al modelo logístico (LucanoRamírez et al. 2014) mediante un método de aproximación no lineal (algoritmo de Levenberg-Marquardt).

\section{Análisis estadísticos}

Para el análisis de la información obtenida para los diferentes años se agrupó por meses. Se calcularon valores promedio y error estándar ( \pm ee) de LT y PT de toda la muestra y para cada uno de los sexos, así como del IGS, FCr, A y DO. Las diferencias entre los valores medios de todas las variables antes mencionadas se evaluaron mediante el análisis de varianza (ANDEVA); previo a estos análisis se verificó el cumplimiento de los supuestos de normalidad y homogeneidad de varianzas, siguiendo a Zar (2010). Cuando los ANDEVA mostraron diferencias significativas considerando un valor de $\alpha=0,05$, se empleó la prueba de rangos múltiples de Student-Newman-Keuls (SNK). Se utilizó la prueba de correlación no paramétrica por rangos de Spearman $\left(r_{\mathrm{s}}\right)$ para evaluar la relación temporal entre IGS y FCr, y entre el IGS y el diámetro promedio mensual de los ovocitos. Las pruebas estadísticas se realizaron utilizando el programa STATISTICA v7.1 (Statsoft 2006) ${ }^{1}$.

${ }^{1}$ StatSoft. 2006. STATISTICA (Data Analysis Software System) version 7.1. <www.statsoft.com> 


\section{RESULTADOS}

\section{COMPOSICIÓN POR TALLAS Y PROPORCIÓN SEXUAL}

Se recolectaron 940 ejemplares de Epinephelus labriformis con intervalos de 20,0 a 40,5 cm LT y de 128 a $1.096 \mathrm{~g}$ PT. Las hembras presentaron longitud mínima, promedio $( \pm$ ee) y máxima de 20,0;30,1 $( \pm 0,14)$ y $40,5 \mathrm{~cm}$, respectivamente, mientras que para los machos fueron de 20,6; $31,3( \pm 0,13)$ y $40,5 \mathrm{~cm}$. En las clases de longitud 21-29 cm LT, las hembras presentaron mayor frecuencia, en tanto que los machos dominaron en 4 de las 5 clases mayores (Fig. 1). Los machos presentaron longitud promedio mayor que las

Tabla 1. Proporción sexual mensual de E. labriformis recolectados en Bahía de Navidad, Jalisco, México. $\mathrm{M}=$ machos; $\mathrm{H}=$ hembras; $\chi^{2}=$ valor del estadístico; $\mathrm{P}=$ valor de probabilidad asociado / Monthly sex ratio of $E$. labriformis collected from Bahía de Navidad, Jalisco, Mexico. $M=$ males; $\mathrm{H}=$ females; $\chi^{2}=$ statistic value; $P=$ associated probability value

\begin{tabular}{lrccrc}
\hline \multicolumn{1}{c}{ Mes } & Machos & Hembras & M:H & \multicolumn{1}{c}{$\chi^{2}$} & $P$ \\
\hline Enero & 10 & 14 & $1,0: 1,4$ & 0,67 & 0,413 \\
Febrero & 6 & 18 & $1,0: 3,0$ & 6,00 & 0,014 \\
Marzo & 33 & 71 & $1,0: 2,2$ & 13,80 & 0,001 \\
Abril & 64 & 25 & $1,0: 0,4$ & 17,09 & 0,001 \\
Mayo & 173 & 171 & $1,0: 1,0$ & 0,01 & 0,920 \\
Junio & 52 & 13 & $1,0: 0,3$ & 23,40 & 0,001 \\
Julio & 17 & 14 & $1,0: 0,8$ & 0,29 & 0,590 \\
Agosto & 13 & 27 & $1,0: 2,1$ & 4,90 & 0,026 \\
Septiembre & 11 & 68 & $1,0: 6,2$ & 41,13 & 0,001 \\
Octubre & 8 & 16 & $1,0: 2,0$ & 2,67 & 0,102 \\
Noviembre & 9 & 45 & $1.0: 5,0$ & 24,00 & 0,001 \\
Diciembre & 23 & 39 & $1,0: 1,7$ & 4,13 & 0,042 \\
\hline
\end{tabular}

hembras $\left(\mathrm{F}_{1,935}=30,6 ; P<0,001\right)$. El peso total varió para las hembras entre 129 y $949 \mathrm{~g}$, con promedio de $456( \pm 6,76)$ g y para los machos fue entre 128 y $1.096 \mathrm{~g}$, con promedio de $520( \pm 7,16) \mathrm{g}$

De los peces recolectados, 521 fueron hembras y 419 machos. La proporción general de sexos fue de 1,3:1,0 (H:M) lo que esta sesgado a las hembras $\left(\chi^{2}=11,07 ; P<\right.$ $0,001 ; \mathrm{gl}=1)$. En cuanto a la proporción sexual mensual se observó que en 8 de los 12 meses las hembras fueron más abundantes que los machos (Tabla 1). Además, se presentó que el número de hembras fue disminuyendo según aumenta la longitud de las mismas (Tabla 2).

Tabla 2. Proporción sexual por clase de longitud (LT) de E. labriformis recolectados en Bahía de Navidad, Jalisco, México. $\mathrm{M}=$ machos; $\mathrm{H}=$ hembras; $\boldsymbol{X}^{2}=$ valor del estadístico; $\boldsymbol{P}=$ valor de probabilidad asociado / Sex ratio by length class of $E$. labriformis collected from Bahía de Navidad, Jalisco, Mexico. $\mathrm{M}=$ males; $\mathrm{H}=$ females; $\chi^{2}=$ statistic value; $P=$ associated probability value

\begin{tabular}{cccccc}
\hline $\begin{array}{c}\text { Clase de } \\
\text { talla }\end{array}$ & Machos & Hembras & M:H & $\chi^{2}$ & $P$ \\
\hline$<23$ & 5 & 45 & $1,0: 9,0$ & 32,00 & 0,001 \\
25 & 23 & 37 & $1,0: 1,6$ & 3,27 & 0,071 \\
27 & 41 & 83 & $1,0: 2,0$ & 14,23 & 0,001 \\
29 & 99 & 115 & $1,0: 1,2$ & 1,20 & 0,273 \\
31 & 128 & 114 & $1,0: 0,9$ & 0,81 & 0,368 \\
33 & 78 & 88 & $1,0: 1,1$ & 0,60 & 0,439 \\
35 & 31 & 30 & $1,0: 1,0$ & 0,02 & 0,888 \\
$37>$ & 14 & 9 & $1,0: 0,6$ & 1,09 & 0,294 \\
\hline
\end{tabular}

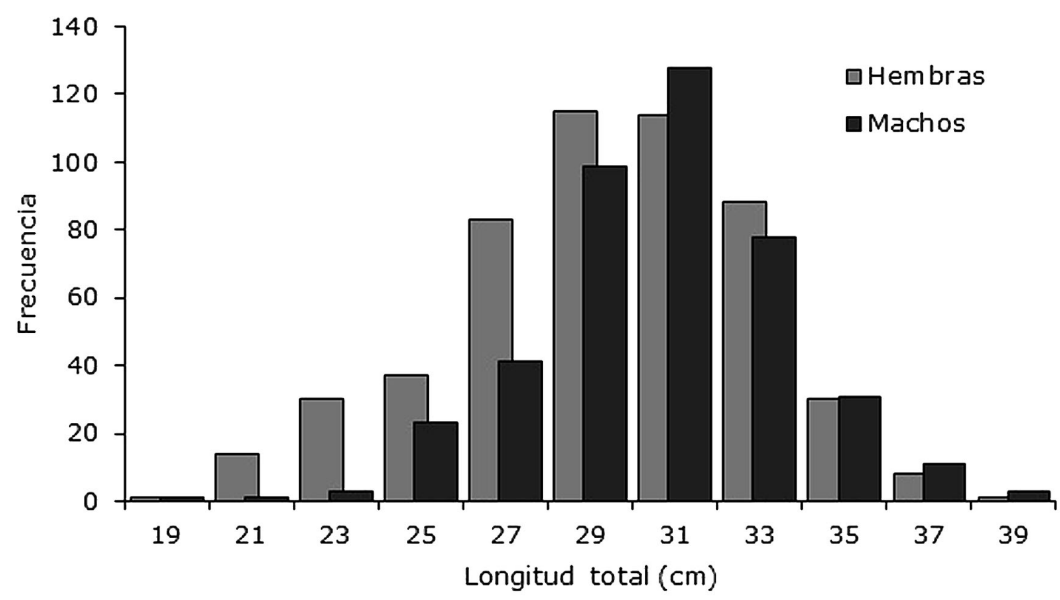

Figura 1. Frecuencia de longitudes de hembras y machos de E. labriformis capturados en Bahía de Navidad, Jalisco, México / Length frequency of females and males of E. labriformis captured from Bahía de Navidad, Jalisco, Mexico 


\section{TEMPORADA REPRODUCTIVA}

El estadio inmaduro se presentó en todos los meses; en las hembras se registraron porcentajes altos en enero, julio y octubre, en machos, en febrero, marzo, julio y noviembre. El estadio en desarrollo registró máximos porcentajes de abril a junio para hembras y para machos en abril, mayo y diciembre. El estadio maduro presentó los mayores porcentajes en las hembras en abril y mayo, y en los machos en abril y agosto. El estadio desovado se observó en la mayoría de los meses en ambos sexos (Fig. 2).
Se presentó una sincronía entre los valores promedio del IGS de hembras y machos $\left(r_{\mathrm{s}}=0,71 ; P=0,009 ; \mathrm{n}=\right.$ 12). Los valores máximos del IGS de hembras y machos se presentaron en abril y agosto. El ANDEVA mostró diferencias significativas entre los valores promedio mensuales del IGS en hembras $\left(\mathrm{F}_{11,508}=3,94 ; P<0,001\right)$ y machos $\left(\mathrm{F}_{11,405}=2,56 ; P=0,005\right)$. En las hembras, la prueba de contrastes múltiples SNK identificó 2 grupos, el promedio menor se registró en julio y el máximo en abril, y en los machos solo se identificó un grupo (Fig. 3). El IGS de hembras es mayor que el de machos $\left(\mathrm{F}_{1,935}=83,6 ; P<0,001\right)$.
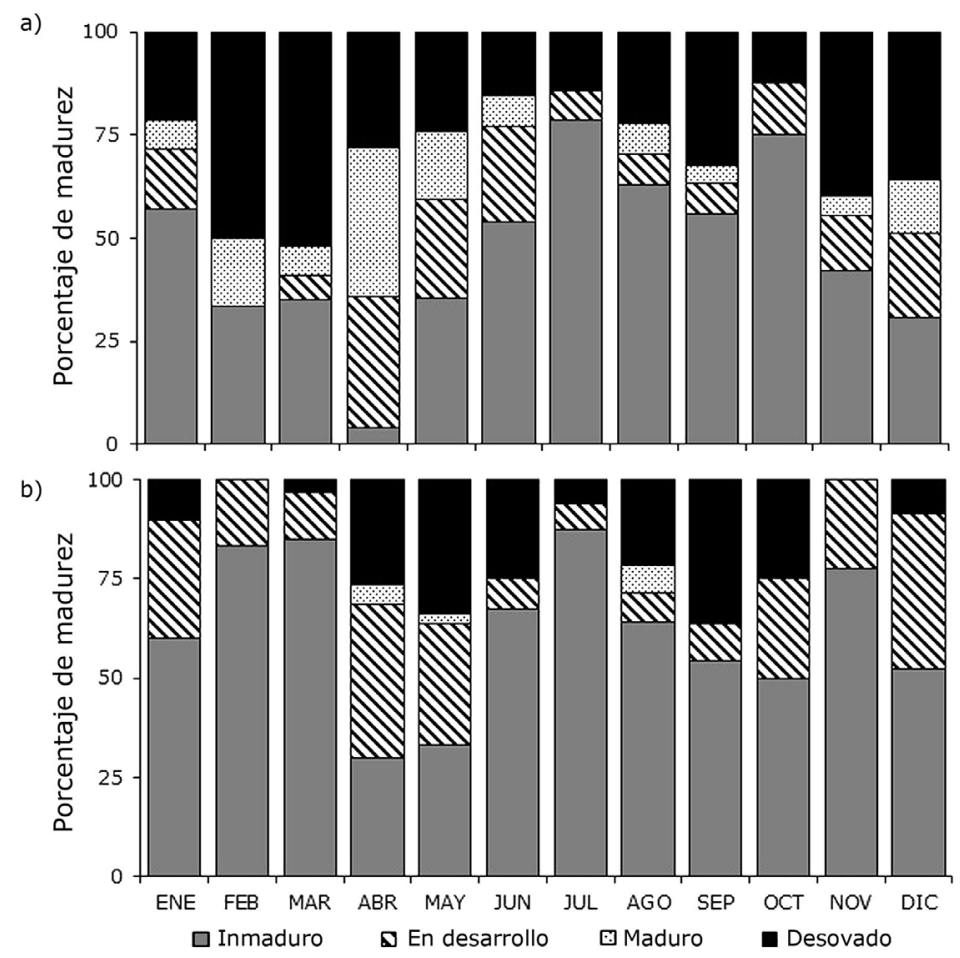

Figura 2. Porcentaje mensual de los estadios de madurez gonádica en hembras (a) y machos (b) de E. labriformis capturados en Bahía de Navidad, Jalisco, México / Monthly percentages of gonad maturity stages in females (a) and males (b) of E. labriformis captured from Bahía de Navidad, Jalisco, Mexico

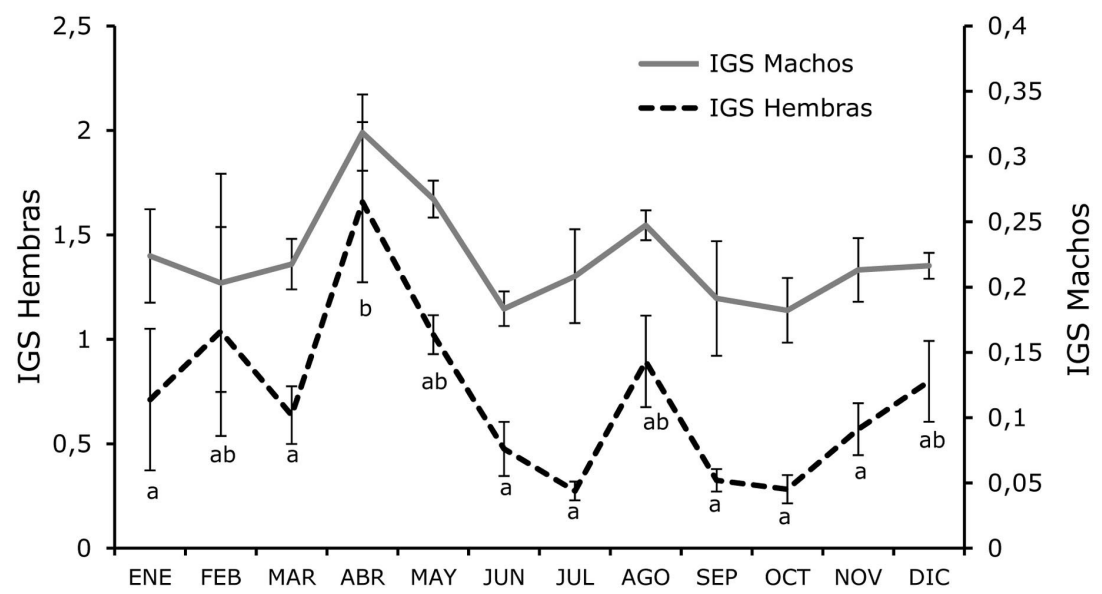

Figura 3. Promedio ( \pm error estándar) mensual del índice gonadosomático (IGS) de hembras y machos de E. Iabriformis recolectados en Bahía de Navidad, Jalisco, México. Las letras indican grupos homogéneos con la prueba de SNK / Monthly means ( \pm standard error) of gonadosomatic index (IGS) for females and males of E. labriformis collected from Bahía de Navidad, Jalisco, Mexico. Letters indicate homogeneous groups with the SNK test 
Se analizó la variación mensual del diámetro promedio de los ovocitos y se encontraron diferencias significativas $\left(\mathrm{F}_{11,2886}=14,99 ; P<0,001\right)$. La prueba de SNK diferenció 5 grupos, el promedio máximo se presentó en marzo $(196,41 \pm$ $9,57 \mu \mathrm{m})$, seguido de abril $(187,21 \pm 1,75 \mu \mathrm{m})$ y el mínimo en julio $(53,11 \pm 1,75 \mu \mathrm{m})$. Se encontró correlación entre el IGS de hembras y el diámetro medio de los ovocitos $\left(r_{\mathrm{s}}=\right.$ 0,$69 ; P=0,014 ; \mathrm{n}=12$ ) (Fig. 4).

Los valores mínimos del FCr de hembras y machos se presentaron en febrero. En los machos el FCr mostró valores semejantes de mayo a octubre y en diciembre; a su vez en las hembras el FCr se incrementó de manera sostenida de febrero a agosto (con un descenso en julio). El ANDEVA encontró diferencias significativas tanto en las hembras $\left(\mathrm{F}_{11,508}=9,2 ; P<0,001\right)$, como en los machos
$\left(\mathrm{F}_{11,405}=4,3 ; P<0,001\right)$. En ambos sexos la prueba de SNK identificó algunas superposiciones; en hembras la mayor diferencia se observó entre febrero y agosto, mientras que en los machos se presentó entre febrero y abril (Fig. 5). Si bien no se encontró correlación temporal significativa entre el FCr e IGS en hembras $\left(r_{\mathrm{s}}=-0,203 ; P=0,520 ; \mathrm{n}=12\right)$ ni en machos $\left(r_{\mathrm{s}}=-0,301 ; P=0,340 ; \mathrm{n}=12\right)$, la tendencia observada fue inversa.

\section{DESCRIPCIÓN MICROSCÓPICA DE LAS GÓNADAS}

Se midió el área de los ovarios y se observaron diferencias significativas entre los promedios para cada estadio de madurez $\left(\mathrm{F}_{3,91}=8,5 ; P<0,001\right)$. La prueba SNK indicó que el área promedio del ovario inmaduro $\left(19,5 \pm 3,8 \mathrm{~mm}^{2}\right)$ fue significativamente menor, en tanto no hubo diferencias

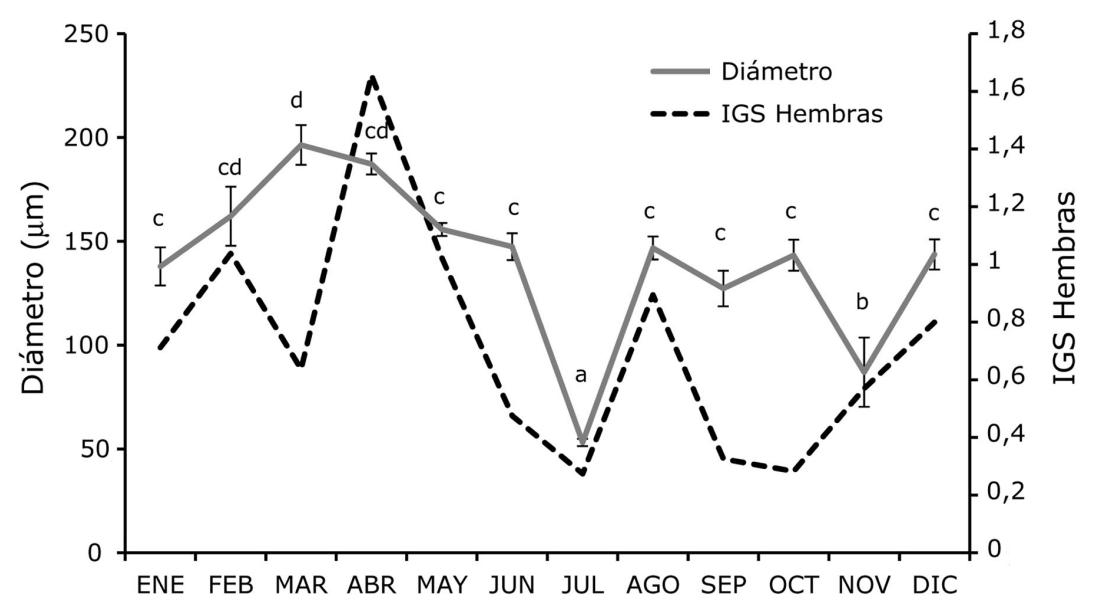

Figura 4. Promedio mensual del índice gonadosomático (IGS) y diámetro del ovocito ( \pm error estándar) en hembras de $E$. labriformis recolectados en Bahía de Navidad, Jalisco, México. Las letras indican grupos homogéneos con la prueba de SNK / Monthly means gonadosomatic index (IGS) and oocyte diameter ( \pm standard error) in E. labriformis females collected from Bahía de Navidad, Jalisco, Mexico. Letter indicate homogeneous groups with the SNK test

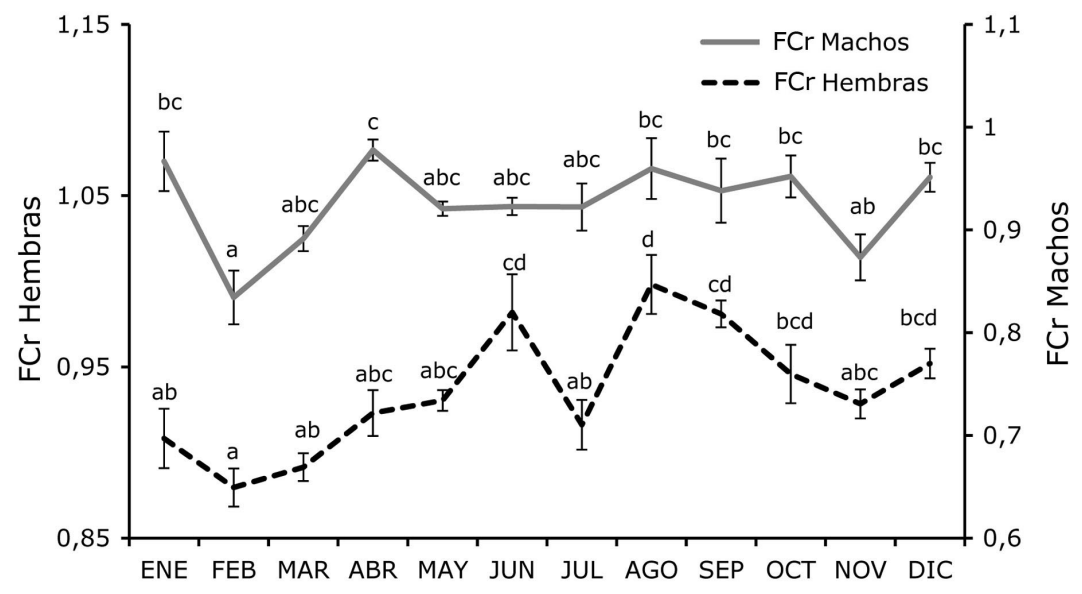

Figura 5. Promedio ( \pm error estándar) mensual del factor de condición relativo $(\mathrm{FCr})$ de hembras y machos de $E$. labriformis recolectados en Bahía de Navidad, Jalisco, México. Las letras indican grupos homogéneos con la prueba de SNK / Monthly means ( \pm standard error) of the relative condition factor ( $\mathrm{FCr}$ ) for females and males of $E$. labriformis collected from Bahía de Navidad, Jalisco, Mexico. Letters indicate homogeneous groups with the SNK test 
estadísticas entre las áreas del ovario en desarrollo $(49,0 \pm$ $\left.4,4 \mathrm{~mm}^{2}\right)$, maduro $\left(59,2 \pm 6,3 \mathrm{~mm}^{2}\right)$ y desovado $(38,0 \pm 5,7$ $\mathrm{mm}^{2}$ ). Este resultado refleja que después de que el ovario entra en el estadio en desarrollo, el aumento que se genera en los siguientes estadios de madurez es mínimo.

Estadio inmaduro: La túnica ovárica es relativamente delgada y las lamelas son compactas, están bien organizadas y definidas en forma de cordones, en donde solo se presentaron ovocitos en crecimiento primario, con diámetro promedio de 54,3 $\pm 0,91 \mu \mathrm{m}$ (Fig. 6a). Estadio en desarrollo: La túnica es relativamente más gruesa que en el estadio previo; la extensión de las lamelas aumentó y el espacio entre lamelas se redujo; se presentaron ovocitos en crecimiento primario $(51,2 \%)$, además de ovocitos en las fases de alveolos corticales $(3,4 \%)$ con diámetro promedio de $142,1 \pm 1,69 \mu \mathrm{m}$, vitelogénesis primaria $(12,8 \%)$ con diámetro de 205,4 $\pm 1,65 \mu \mathrm{m}$; y vitelogénesis secundaria (32,5\%) con diámetro de 296,7 $\pm 3,35 \mu \mathrm{m}$. Estadio maduro: Se extiende el proceso de vitelogénesis en gran parte de los ovocitos, se observaron ovocitos primarios $(47,3 \%)$, alveolos corticales $(5,0 \%)$, vitelogénesis primaria $(18,5 \%)$, vitelogénesis secundaria $(26,6 \%)$, vitelogénesis terciaria

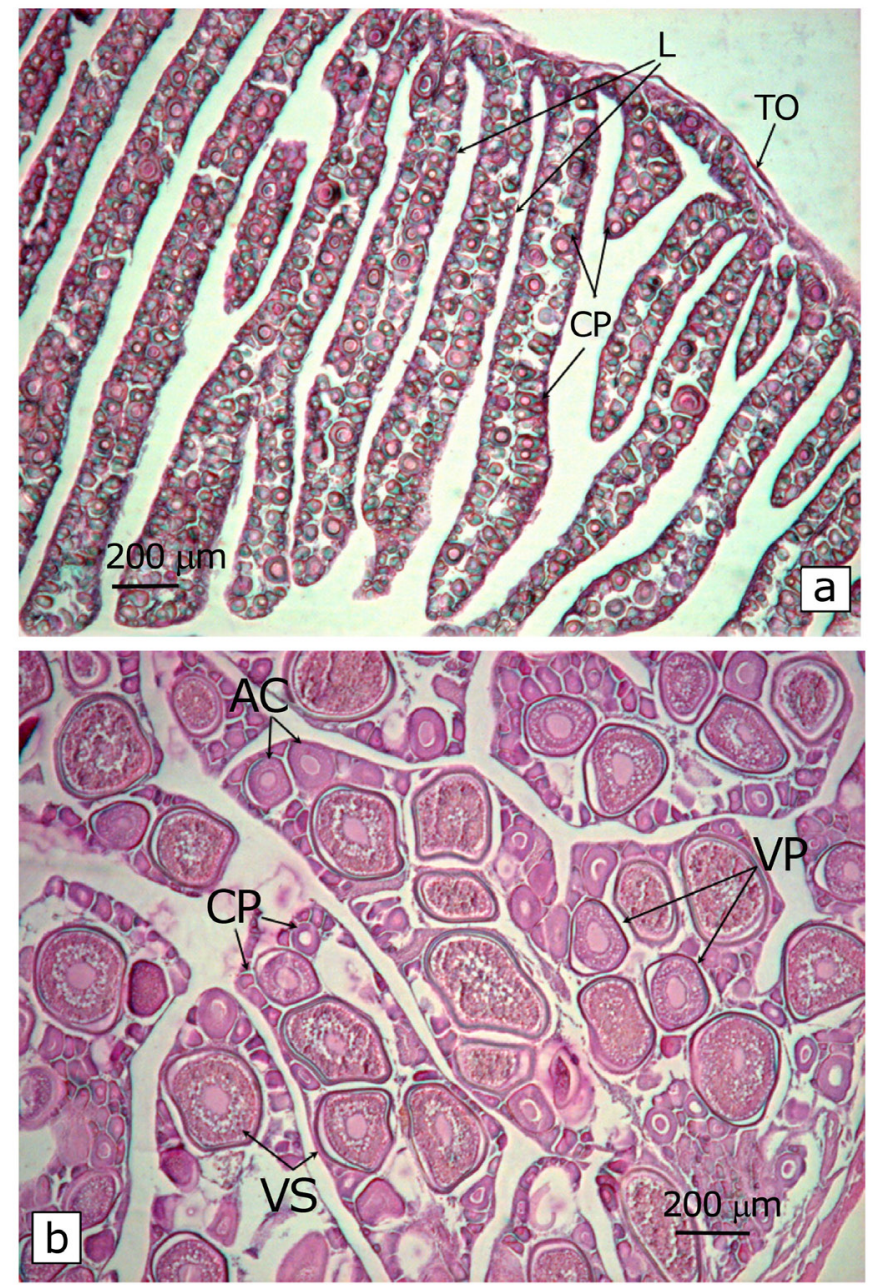

$(1,8 \%)$ con diámetro de $191,1 \pm 6,66 \mu$ m y ovocitos con vesícula germinal en migración $(1,0 \%)$ con diámetro de $240,1 \pm 7,73 \mu \mathrm{m}$, además de ovocitos hidratados (Fig. 6b). Estadio desovado: La túnica continúa engrosada y se perdió la estructura compacta y organizada de las lamelas y los ovocitos, ya que entre ellos se pueden observar espacios vacíos; se distinguen ovocitos en crecimiento primario $(73,4 \%)$, alveolos corticales $(6,1 \%)$, vitelogénesis primaria $(8,5 \%)$ y vitelogénesis secundaria $(11,9 \%)$, además se observaron pocos folículos postovulatorios. El ANDEVA detectó diferencias significativas entre los diámetros promedio de los ovocitos en sus distintas fases de desarrollo $\left(\mathrm{F}_{6,3008}=307,9 ; P<0,01\right)$; los menores diámetros los presentaron los ovocitos con menor grado de desarrollo y los ovocitos con mayor maduración tuvieron los mayores diámetros. También se encontraron diferencias en el diámetro de los ovocitos presentes en los 4 estadios de maduración gonadal $\left(\mathrm{F}_{3,2973}=109,7 ; P<0,01\right)$; el menor diámetro promedio de los ovocitos lo presentó el ovario inmaduro y los mayores diámetros ocurrieron en los estadios en desarrollo, maduro y desovado. Se describieron 7 fases de ovocitos, por lo tanto su desarrollo es asincrónico.
Figura 6. Ovarios inmaduro (a) y maduro (b) de $E$. labriformis. $\mathrm{TO}=$ túnica ovárica, $\mathrm{L}=$ lamela, $\mathrm{CP}=$ ovocitos en crecimiento primario, $\mathrm{AC}=$ alvéolos corticales, $\mathrm{VP}=$ vitelogénesis primaria, VS= vitelogénesis secundaria / Immature (a) and mature ovaries (b) of E. labriformis. $\mathrm{TO}=$ ovary tunic, $\mathrm{L}=$ lamella, $\mathrm{CP}=$ primary growth oocytes, $\mathrm{AC}=$ cortical alveolar, $\mathrm{VP}=$ primary vitellogenic, $\mathrm{VS}=$ secondary vitellogenic 
Los testículos se encontraron estructurados por lóbulos; cada uno contiene agrupaciones de células germinales en diferente fase de maduración organizadas en cistos, en los cuales se lleva a cabo la espermatogénesis. Después de completar su formación, los espermatozoides se concentran en la luz de los lóbulos (Fig. 7a). A este tipo de organización que tienen las células del testículo se le denomina desarrollo lobular. Se midió el área del testículo y se comparó entre los distintos estadios de maduración, no se encontraron diferencias significativas $\left(\mathrm{F}_{3,196}=0,88 ; P=0,44\right)$ entre los estadios: inmaduros $\left(11,9 \pm 1,4 \mathrm{~mm}^{2}\right)$, en desarrollo $(12,5 \pm$ $\left.0,7 \mathrm{~mm}^{2}\right)$, maduro $\left(14,0 \pm 2,8 \mathrm{~mm}^{2}\right)$ y desovado $(14,4 \pm 1,4$ $\mathrm{mm}^{2}$ ). Este resultado en donde no hay diferencias entre las áreas del testículo en los diferentes estadios de maduración puede deberse al comportamiento que tiene esta especie por ser hermafrodita. Comparativamente, el área promedio del ovario en cada uno de los estadios de maduración fue mayor que el área promedio del testículo: inmaduro $\left(\mathrm{F}_{1,62}=5,24 ; P\right.$ $<0,05)$, en desarrollo $\left(\mathrm{F}_{1,138}=136 ; P<0,01\right)$, maduro $\left(\mathrm{F}_{1,26}=\right.$
$29,63 ; P<0,01)$ y desovado $\left(\mathrm{F}_{1,61}=37,35 ; P<0,01\right)$. Esto puede deberse a que las células reproductivas femeninas (ovocitos) son mucho más grandes que las de los machos (espermatozoides), por tanto ocupan un área mayor.

\section{Cuerpos amarillos}

De las 196 muestras analizadas de testículos, el 91\% presentó de una a varias decenas de cuerpos amarillos o marrones (CA). Éstos son de tamaño similar, generalmente de forma circular, oval o incluso irregular. La ubicación de estos cuerpos en la gónada fue un tanto aleatoria (Fig. 7b). Los CA se encontraron en machos de 21,0 a 40,5 cm LT, sin embargo más del $75 \%$ se presentaron en individuos de 27,0 a 34,9 cm LT. El 50\% de los CA se observaron en individuos con gónadas en desarrollo, en los estadios inmaduro (25\%) y desovado (25\%) se encontró el otro 50\%. En un análisis temporal, la mayoría de los CA se presentó entre febrero y junio (excepto abril).
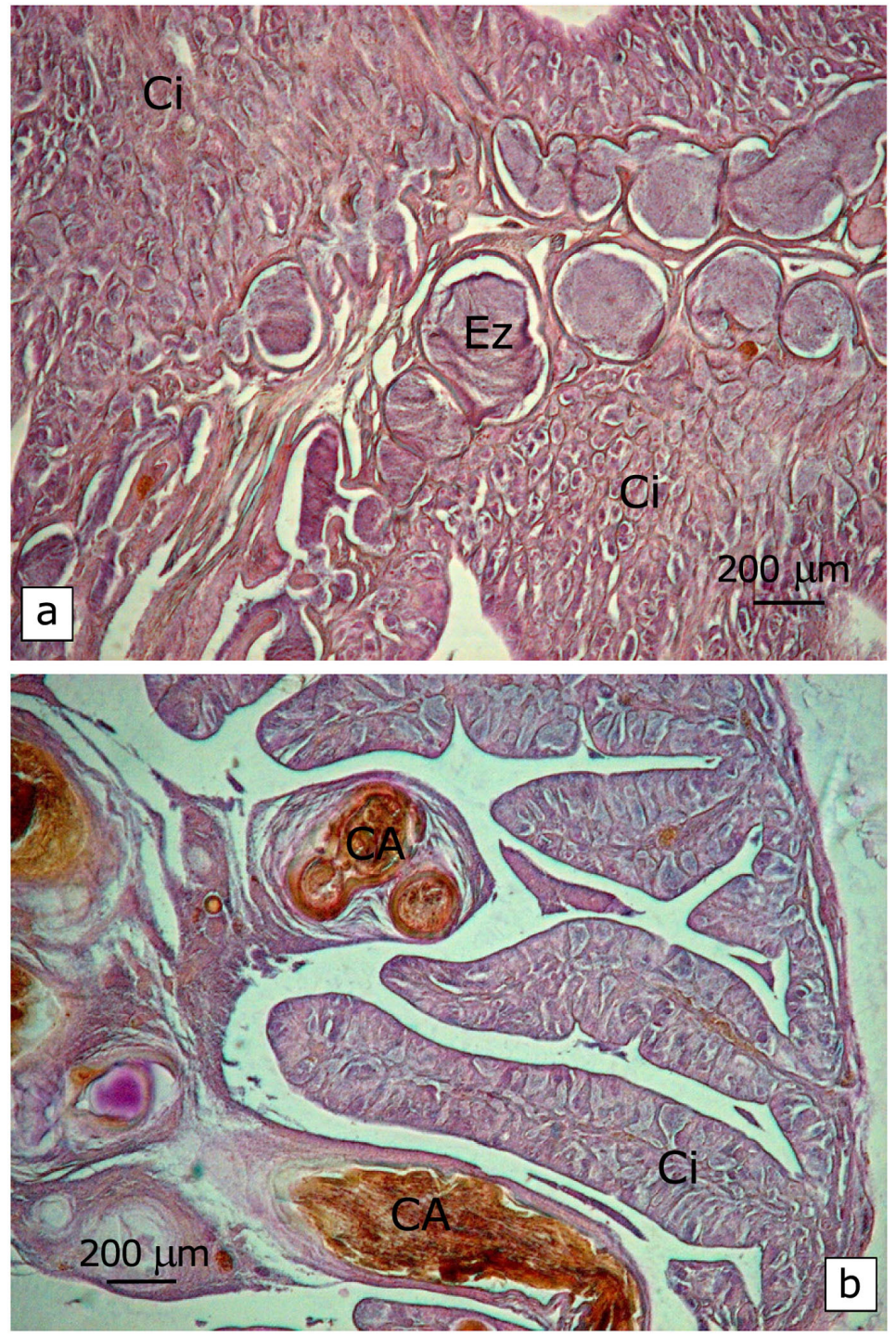

Figura 7. Testículos maduro (a) y en desarrollo (b) de E. labriformis. $\mathrm{Ez}=$ espermatozoides, $\mathrm{Ci}=$ cistos, $\mathrm{CA}=$ cuerpos amarillos / Mature (a) and developing (b) testicles of $E$. labriformis. $\mathrm{Ez}=$ spermatozoa, $\mathrm{Ci}=$ cysts, $\mathrm{CA}=$ yellow bodies 


\section{INDIVIDUOS EN FASE dE Transición}

Se encontraron 33 ejemplares (3,5\% del total estudiado), entre las clases de 26 y $36 \mathrm{~cm}$ LT, con gónadas en fase de transición (o cambio de sexo), en las cuales se observó de manera simultánea la degeneración de ovocitos y la presencia de tejido espermático (Fig. 8). En el ovario de algunas hembras maduras se distinguieron zonas de tejido testicular cerca de la túnica ovárica. Estas regiones de desarrollo espermático no están separadas por ningún tipo de tejido o epitelio limitante, es decir, se encuentran juntas o entremezcladas en la misma gónada. A su vez, en el testículo de algunos machos maduros se encontraron remanentes de ovocitos, generalmente cerca de la túnica albugínea y entre los lóbulos; éstos fueron de color marrón a blanquecino, que es un indicio confiable de la existencia anterior de ovocitos en fase vitelogénica.

\section{ESTIMACión de LA TALLA AL CAMBio de SEXo}

Se observaron hembras inmaduras en las clases de longitud de 19 a $32 \mathrm{~cm} \mathrm{LT}$, los mayores porcentajes ocurrieron en las primeras clases de 19 a $22 \mathrm{~cm}$ LT. Las hembras maduras se agruparon entre $\operatorname{los} 23$ y $35 \mathrm{~cm}$ LT. No se registraron hembras entre los 36 y $39 \mathrm{~cm} \mathrm{LT}$, pero si en la clase de $40 \mathrm{~cm}$ LT. Los machos inmaduros se encontraron entre los 19 y $37 \mathrm{~cm} \mathrm{LT}$. Machos maduros se presentaron entre los 25 y $40 \mathrm{~cm} \mathrm{LT}$, y se distingue un claro incremento en el porcentaje conforme aumenta la longitud. Se observó

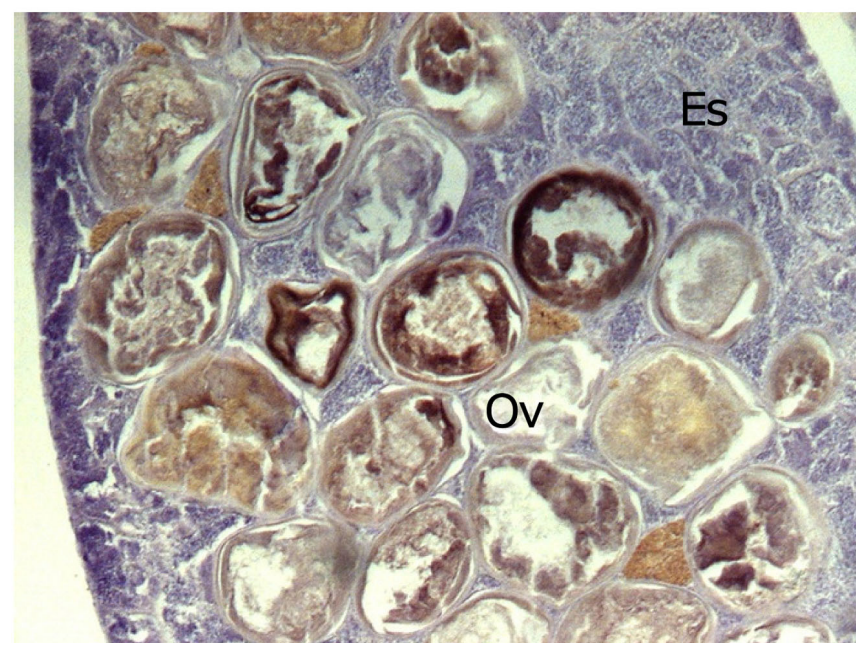

Figura 8. Individuo en transición de E. labriformis que presenta ovocitos en regresión (Ov) y zonas con tejido testicular (Es) / Individual in transition of E. labriformis showing oocytes in regression (Ov) and areas with testicular tissue (Es)

una considerable superposición en la distribución de longitudes entre machos y hembras. Se estima que el cambio de sexo de hembra a macho se inicia a una longitud de 26,0 cm LT ya que los ejemplares en transición más pequeños correspondieron a esa clase de talla (Fig. 9).

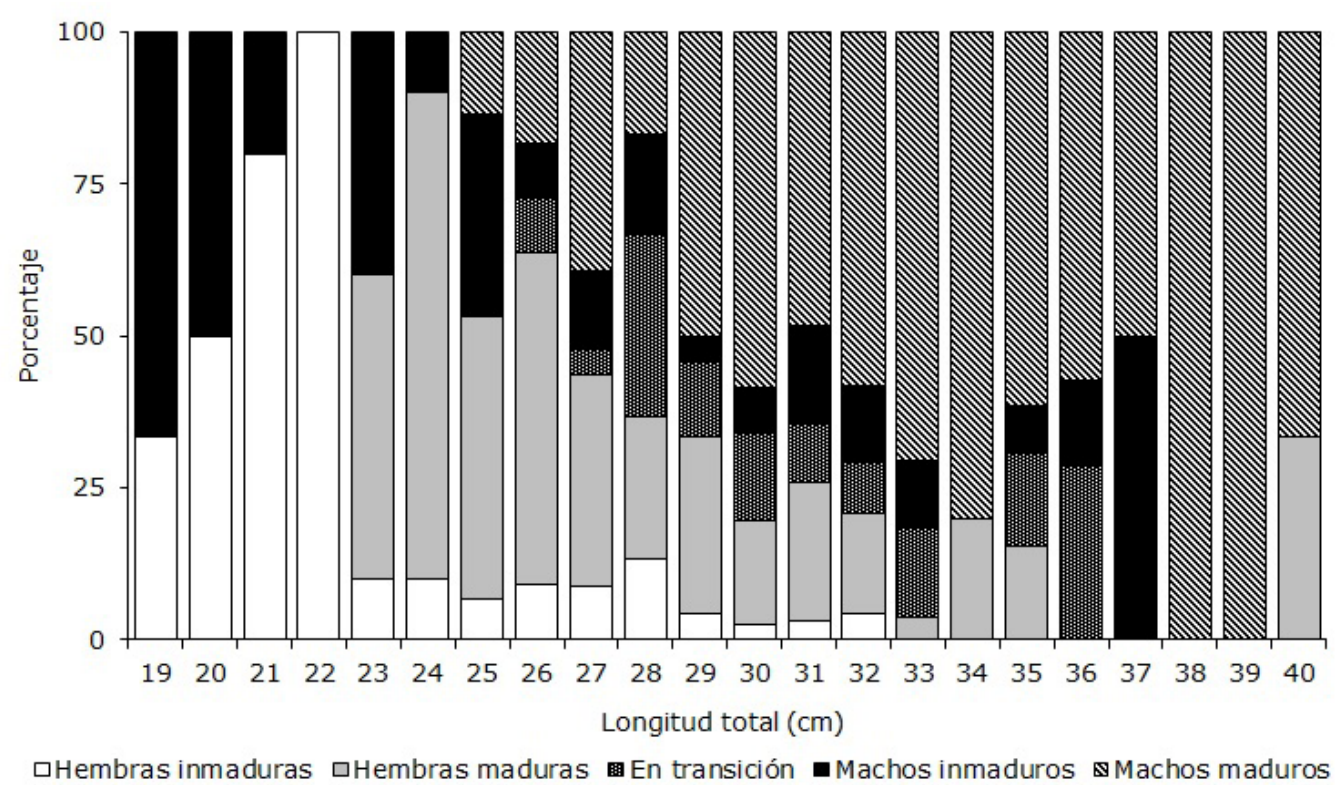

Figura 9. Porcentaje de hembras inmaduras y maduras, ejemplares en transición, y machos inmaduros y maduros por clase de longitud de E. labriformis recolectados en Bahía de Navidad, Jalisco, México / Percentage of immature and mature females, transitional individuals, and immature and mature males per length class of $E$. labriformis collected from Bahía de Navidad, Jalisco, Mexico 


\section{TALLA PROMEdio de MAdUREZ SEXUAL}

Los ejemplares de mayor talla con gónadas inmaduras fueron una hembra de 33,1 cm LT y un macho de 35,0 cm LT. A su vez, los de menor talla con gónadas maduras midieron 23,5 y $25,8 \mathrm{~cm}$ LT, hembra y macho, respectivamente. Del total de ejemplares muestreados, el 50\% de las hembras de E. labriformis alcanzaron la madurez sexual a los 29,6 cm LT; en machos ese parámetro fue estimado en $31,3 \mathrm{~cm}$ LT (Fig. 10). Las hembras maduran a una talla ligeramente menor que los machos.

\section{DisCUSIÓN}

El intervalo de tallas para Epinephelus labriformis en la Bahía de Navidad (20,0-40,5 cm LT) en este trabajo es mayor a los reportados por Cruz-Romero et al. (1987) en Colima (14-23,5 cm LT), y Craig et al. (1999) en Bahía de Banderas (15-30 cm LT), ambos en México. El mayor intervalo de tallas para esta especie (15,5-42,3 cm LT) lo encontró Erisman (2008) en Puerto Vallarta, Jalisco y Loreto BCS, México. Las pequeñas discrepancias en longitud encontradas en los trabajos antes mencionados podrían deberse a diferencias en el tamaño de la muestra, al sitio de recolecta, al arte de pesca utilizado o incluso a diferencias poblacionales (Cruz-Romero et al. 1987, Sadovy \& Shapiro 1987, Craig et al. 1999).

En el presente trabajo la proporción de sexos de $E$. labriformis estuvo dominada por las hembras, Erisman (2008) encontró una situación contraria para la misma especie (2H:3M). Sin embargo, resultados similares a los de este estudio fueron encontrados para otras especies del mismo género, e incluyen a De Martini et al. (2011) en Hawái, quienes reportaron para Epinephelus quernus una proporción sexual de 6:1 (H:M). Al sur del Golfo de México, Caballero-Arango et al. (2008) encontraron para Epinephelus morio una proporción sexual de 1,9:1,0 dominada por las hembras. Giménez-Hurtado et al. (2003) encontraron para E. morio en Yucatán una proporción sexual de 1,5:1,3, y sugirieron que además del tipo de sexualidad de la especie, la explotación pesquera podría estar actuando, al capturar más hembras que machos. Sadovy \& Shapiro (1987) plantearon que las diferencias entre el número de hembras y machos puede depender también de la técnica de muestreo, de las tasas de mortalidad y de crecimiento, así como de la preferencia por un hábitat particular en ambos sexos.

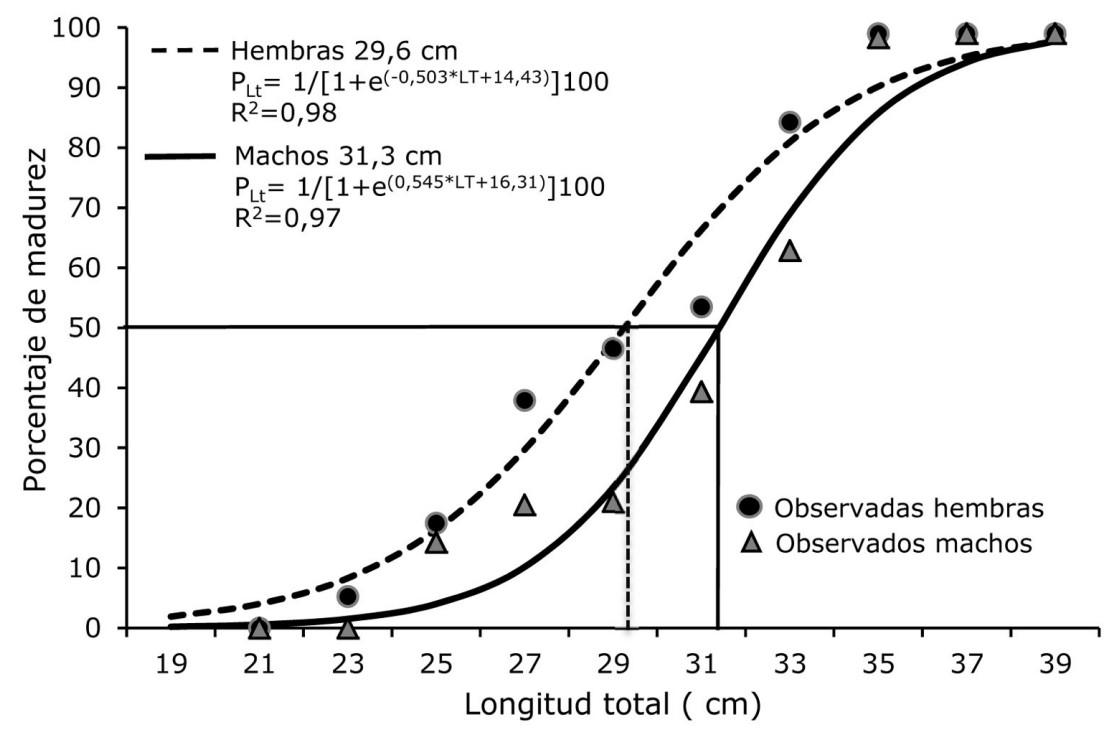

Figura 10. Porcentaje de hembras y machos maduros de E. labriformis capturados en Bahía de Navidad, Jalisco, México / Percentage of mature females and males of E. labriformis captured from Bahía de Navidad, Jalisco, Mexico 
Para E. labriformis, los mayores valores del IGS de hembras y machos se presentaron en abril y agosto; este mismo periodo coincide con la mayor actividad reproductiva que señala Erisman (2008) para la misma especie. Otros autores han encontrado resultados similares para diferentes regiones y otras especies del género Epinephelus. Brulé et al. (1996) para E. morio en el banco de Campeche, Yucatán, encontraron los máximos valores del IGS en marzo. A su vez, De Martini et al. (2011) indicaron que el periodo de desove en E. quernus se extiende de febrero a junio, con máximo en marzo. Para Epinephelus drummondhayi, Brulé et al. (2000) señalaron que los desoves ocurren en abril, mayo y en agosto, en el Golfo de México. En tanto, Bullock et al. (1996) indicaron que la actividad gonadal de Epinephelus flavolimbatus alcanzó su punto máximo entre mayo y septiembre. Shapiro et al. (1993) observaron para Epinephelus guttatus en Puerto Rico, valores máximos del IGS en marzo y agosto. Lluch-Cota et al. (2007) y Hernández-Oldade (2008) señalan que la reproducción en diferentes especies de peces depende de la combinación adecuada de factores ambientales, como la temperatura, la cantidad y la calidad de alimento, la densidad de depredadores, sugiriendo que debe existir una similitud en las temporadas reproductivas de muchas especies para una región dada.

En el área de estudio se presentan períodos de intensas surgencias de febrero a mayo, que provocan alta concentración de clorofila a y una mayor productividad primaria (Ambriz-Arreola et al. 2012). Esta ventana de enriquecimiento temporal tendría beneficios en la progenie de E. labriformis y podría explicar el período de reproducción en estos meses. A su vez, en agosto ya ha comenzado la temporada de lluvias y ciclones provocando escorrentías desde tierra (González-Sansón et al. 2014), que incrementan el flujo en ríos arrastrando nutrientes, y un aumento de su disponibilidad en los ecosistemas costeros. Además, con el inicio de la temporada de lluvias, hay un nivel apreciable de oxígeno disuelto a disposición de los ejemplares que podrían promover la actividad reproductiva (Chellappa et al. 2009, Abe et al. 2013). Estas condiciones podrían explicar parcialmente la existencia de un segundo pulso reproductivo en la especie.

Los valores del IGS en los machos de E. labriformis fueron relativamente bajos. Esta característica también se ha observado en otras especies de serránidos. De Martini et al. (2011) reportan que el peso del testículo en Hyporthodus quernus representa menos del 1\% del peso total del individuo. De igual forma, Tuz-Sulub et al. (2008) señalaron que los machos de Epinephelus striatus presentaron testículos pequeños y bajos valores del IGS. Estos autores consideraron que esta especie se reproduce formando parejas o en grupos muy reducidos. Molloy et al. (2007) mencionaron que este rasgo es típico de especies hermafroditas protóginas, y puede indicar que estas especies realizan desoves individuales o en pareja. Este tipo de desove presenta nula o baja competencia espermática, incluyendo la cantidad de espermatozoides liberados, estos machos dirigen su estrategia a defender el territorio de otros machos, lo que involucra la obtención de nuevos recursos como más espacio, alimento y pareja para la reproducción (Sadovy et al. 1994). Además, Erisman (2008) observó, mediante buceo, grupos pequeños de peces compuestos entre 2 y 6 individuos en arrecifes localizados en Loreto, BCS, México durante la época reproductiva. Esto podría explicar el valor bajo del IGS en machos de E. labriformis.

El FCr en E. labriformis de ambos sexos presentó escasa variación temporal. Lo anterior puede indicar que la reproducción no afecta de manera importante la condición del organismo, aunque también podría explicarse si esta especie presenta un comportamiento de alimentación constante, esto también lo vieron reflejado González \& Oyarzún (2002) en Pinguipes chilensis. En este sentido, Estrada-Godínez et al. (2014) mencionaron que los reproductores de Mycteroperca rosacea, así como de otras especies de serránidos y peces tropicales, no dejan de alimentarse durante las etapas de maduración y desove. A su vez, Chyrasekhara \& Krishnan (2011) encontraron que Epinephelus diacanthus mantuvo valores relativamente constantes en el FCr conforme avanzó el periodo reproductivo.

En las gónadas de E. labriformis se identificaron cuerpos amarillos, esta característica se ha reportado en otras especies de serránidos (De Martini et al. 2011, ChongMontenegro 2014). La presencia de cuerpos amarillos puede tener diferentes orígenes y en última instancia, ser la acumulación de pigmentos de diferentes procesos. Los pigmentos involucrados pueden ser la hemosiderina. La hemosiderina es producto de la degradación de la hemoglobina, que comúnmente forma cuerpos de color amarillo-marrón en el bazo e hígado (Wolke et al. 1985) y en los sitios de hemorragia o congestión en cualquier tejido, incluyendo el gonadal (Lillie \& Fullmer 1976).

La estructura de la gónada de E. labriformis es similar a la descrita para otras especies de serránidos hermafroditas (Shapiro et al. 1993, Erisman et al. 2008, Díaz-Madrid et al. 2012). En E. labriformis, el análisis histológico permitió identificar ejemplares en transición, los cuales presentaron longitudes entre 26 y $36,9 \mathrm{~cm}$. Para esta misma especie, Erisman (2008) encontró ejemplares en transición entre los 23 y $34,6 \mathrm{~cm}$. La talla a la que ocurre el cambio de sexo puede ser una característica específica para cada especie (Sadovy \& Shapiro 1987). Bullock et al. (1996) señalaron que la transición de sexo en E. flavolimbatus ocurrió entre los 52,5 y 89,8 cm, y solo encontraron 7 individuos en esta fase entre 1.090 para los cuales se registró el sexo. Debido a este número reducido suponen que la transición ocurre de forma rápida, aunque también consideran que pudo influir un esfuerzo de muestreo insuficiente. Sin embargo, Giménez-Hurtado et al. (2003), encontraron 173 ejemplares de E. morio (que representan el 1,5\% de todos los individuos muestreados) de entre 30 y $35 \mathrm{~cm}$ en etapa de transición, en Yucatán. 
Los valores de longitud promedio de maduración sexual observados en este trabajo son cercanos y menores a la longitud promedio de captura, tanto en hembras como en machos (30,1 y 31,0 cm, respectivamente), lo que permite suponer que muchos de los ejemplares recolectados posiblemente ya habrían tenido al menos un evento reproductivo. La longitud promedio de maduración de E. labriformis en este estudio fue mayor a la reportada por Erisman (2008), quien menciona que la especie tiende a madurar a una longitud relativamente pequeña (17 y $23 \mathrm{~cm}$ longitud estándar, para hembras y machos, respectivamente). Este hecho podría estar asociado con problemas de sobrepesca. Shapiro et al. (1993) notaron una reducción en la longitud promedio de E. guttatus en Puerto Rico, como consecuencia del impacto de la presión de pesca. Según Chiappone et al. (2000), la pesca intensiva sobre los serránidos puede provocar, no solo una baja en la densidad y biomasa en las especies, sino también una reducción en la longitud promedio de los ejemplares. También Sluka et al. (1997), sostienen que la pesca es el factor que más influye en las variaciones en la abundancia y en las longitudes de los meros.

Craig et al. (1999) y Erisman (2008) ya habían reportado para E. labriformis la presencia de hermafroditismo protógino. El presente trabajo confirma este tipo de patrón sexual con base en cinco características: a) la organización de la gónada, en donde la línea germinal de cada sexo no está delimitada, se encuentra entremezclada, b) se identificaron individuos en la fase de cambio de sexo, c) mayor número de hembras en las clases de menor longitud, d) mayor proporción de hembras que de machos, e) menor longitud promedio de maduración y de captura en las hembras que en los machos.

El patrón sexual protógino que presentan E. labriformis y otros serránidos los hacen vulnerables a la sobreexplotación debido a que los machos son más grandes y menos abundantes que las hembras, y se conoce que la actividad pesquera frecuentemente captura ejemplares más grandes (Rhodes \& Sadovy 2002). Esta situación pone en riesgo a las especies que tienen este tipo de hermafroditismo, sobre todo a las que se encuentran sometidas a presiones de pesca mediana a intensa y más aún en sitios en donde no existen mecanismos eficientes de regulación o manejo pesquero, o incluso en los que no se tiene un registro confiable de las estadísticas pesqueras. Por lo expuesto, es importante diseñar y/o intensificar planes regulares de monitoreo e implementar medidas adecuadas de manejo pesquero para esta especie, así como para otros serránidos hermafroditas.

\section{Agradecimientos}

Este estudio fue financiado por la Universidad de Guadalajara. Los autores agradecen a Daniel Kosonoy, Gerardo Kosonoy y Manuel Díaz, su ayuda en la realización de las actividades de pesca; a las cooperativas pesqueras "Rivera Melaque" y "Punta Farallón" por el uso de sus instalaciones y a los estudiantes de la Universidad de Guadalajara que colaboraron en los muestreos.

\section{LITERATURA CITADA}

Abe K, N Nakagawa, KAbo \& M Tsujino. 2013. High nutrients in the coastal area after heavy rain observed in the central Seto Inland Sea in July 2012. Journal of Oceanography 69(2): 269-275.

Aburto-Oropeza O, B Erisman, V Valdez-Ornelas, G Dabemann, E Torreblanca-Ramírez, J Silva-Ramírez \& G Ortuño-Manzanarez. 2008. Serránidos de importancia comercial del Golfo de California: ecología, pesquerías y conservación. Ciencia y Conservación 2009(1): 1-23.

Aguilar-Palomino B, C Pérez-Reyes, F Galván-Magaña \& LA Abítia-Cárdenas. 2001. Ictiofauna de la Bahía de Navidad, Jalisco, México. Revista de Biología Tropical 49(1): 173-190.

Ambriz-Arreola I, J Gómez-Gutiérrez, C Franco-Gordo, BE Lavaniegos \& E Godínez-Domínguez. 2012. Influence of coastal upwelling-downwelling variability on tropical euphausiid abundance and community structure in the inshore Mexican central Pacific. Marine Ecology Progress Series 451: 119-136.

Brown-Peterson NJ, DM Wyanski, F Saborido-Rey, BJ Macewicz \& SK Lowerre-Barbieri. 2011. A standardized terminology for describing reproductive development in fishes. Marine and Coastal Fisheries: Dynamics, Management, and Ecosystem Science 3(1): 52-70.

Brulé T, N Maldonado-Montiel, L Rodríguez-Canche \& G Mexicano-Cintora. 1996. Aspects of the reproductive and trophic biology of the red grouper, Epinephelus morio (Valenciennes, 1828), from Campeche Bank, Yucatan, Mexico. Proceedings of the Gulf and Caribbean Fisheries Institute 44: 39-55.

Brulé T, T Colás-Marrufo, A Tuz-Sulub \& C Déniel. 2000. Evidence for protogynous hermaphroditism in the serranid fish Epinephelus drummondhayi (Perfiformes: Serranidae) from the Campeche bank in the southern Gulf of Mexico. Bulletin of Marine Science 66(2): 513-521.

Bullock LH, MF Godcharles \& RE Crabtree. 1996. Reproduction of yellowedge grouper, Epinephelus flavolimbatus, from the eastern Gulf of Mexico. Bulletin of Marine Science 59: 216-224.

Caballero-Arango D, T Brulé, JL Montero-Muñoz \& T Colás-Marrufo. 2008. Análisis preliminar sobre la variación de algunos parámetros reproductivos del mero rojo del Banco de Campeche en el periodo 1989-2004. Proceedings of the Gulf and Caribbean Fisheries Institute 60: 247-253. 
Chellappa S, RM Bueno, T Chellappa, NT Chellappa \& VMFA Val. 2009. Reproductive seasonality of the fish fauna and limnoecology of semi-arid Brazilian reservoirs. Limnologica - Ecology and Management of Inland Waters 39(4): 325-329.

Chiappone M, R Sluka \& K Sullivan. 2000. Groupers (Pisces: Serranidae) in fished and protected areas of the Florida Keys, Bahamas and northern Caribbean. Marine Ecology Progress Series 198: 261-272.

Chong-Montenegro CP. 2014. Estudio del ciclo gonadal del camotillo (Paralabrax albomaculatus) en la provincia insular de Galápagos. Tesis de Licenciatura, Facultad de Ingeniería Marítima, Ciencias Biológicas, Oceánicas y Recursos Naturales, Guayaquil, 99 pp.

Chyrasekhara RA \& L Krishnan. 2011. Biochemical composition and changes in biological indices associated with maturation of the ovary in the spiny cheek grouper Epinephelus diacanthus (Valenciennes, 1828). Indian Journal of Fisheries 58(2): 45-52.

Craig MT, DJ Pondella \& JC Hafner. 1999. Analysis of age and growth in two eastern Pacific groupers (Serranidae: Epinephelinae). Bulletin of Marine Science 65: 807-814.

Craig MT, YJ Sadovy de Mitcheson \& PC Heemstra. 2011. Groupers of the world: A field and market guide, $424 \mathrm{pp}$. NISC, Grahamstown.

Cruz-Romero M, E Espino-Barr \& A García-Boa. 1987. Edad y crecimiento en la cabrilla Epinephelus labriformis (Jenyns, 1843) en el estado de Colima. Acta Científica Potosina 9: 165-176.

De Martini EE, AR Everson \& RS Nichols. 2011. Estimates of body sizes at maturation and at sex change, and the spawning seasonality and sex ratio of the endemic Hawaiian grouper (Hyporthodus quernus, F. Epinephelidae). Fishery Bulletin 109(1): 123-134.

Díaz-Madrid LC, AJ Vega \& YA Robles. 2012. Descripción macro y microscópica de las gónadas de la cherna roja: Epinephelus acanthistius (Serranidae) capturadas en el Parque Nacional Coiba, Pacífico, Panameño. Tecnociencia 14(2): 5-21.

Erisman BE. 2008. Reproductive biology and evolution of epinephelid and serranid fishes (Perciformes, Epinephelidae, Serranidae). PhD Thesis in Marine Biology, University of California, San Diego, La Jolla. <www.scholarship.org/uc/ item/5d59v5fn\#page-77> [UC San Diego Electronic Theses and Dissertations]

Estrada-Godínez JA, M Maldonado-García, V Gracia-López, M Carrillo, R Rebollar-Prudente \& M SpanopoulosZarco. 2014. Efecto del fotoperiodo y la temperatura sobre la composición bioquímica en reproductores silvestres de la cabrilla sardinera, Mycteroperca rosacea (Streets, 1877). Latin American Journal of Aquatic Research 42(1): 85-96.

Everson AR, HA Williams \& BM Ito. 1989. Maturation and reproduction in two Hawaiian eteline snappers, Uku, Aprion virescens, and Onaga, Etelis coruscans. Fishery Bulletin 87: 877-888.

Froese R. 2006. Cube law, condition factor and weight-length relationships: history, meta-analysis and recommendations. Journal of Applied Ichthyology 22(4): 241-253.

Giménez-Hurtado E, C Moreno, V García, R Burgos-Rosas \& S Alfonso-Chiroldes. 2003. Reproducción y fecundidad de la cherna americana (Epinephelus morio) en el banco de Campeche, México. Oceánides 18(1): 13-21.
González P \& C Oyarzún. 2002. Variabilidad de índices biológicos en Pinguipes chilensis Valenciennes 1833 (Perciformes, Pinguipeididae): ¿Están realmente correlacionados? Gayana 66(2): 249-253.

González-Sansón G, C Aguilar-Betancourt, D KosonoyAceves, G Lucano-Ramírez, S Ruiz-Ramírez, JR FloresOrtega, A Hinojosa-Larios \& FA Silva-Bátiz. 2014. Composición por especies y tallas de los peces en la laguna Barra de Navidad, Pacífico central mexicano. Revista de Biología Tropical 62(1): 129-144.

Gotshall DW. 1998. Sea of Cortez marine animals: A guide to the common fishes and invertebrates, Baja California to Panama, 110 pp. Sea Challengers, Monterey.

Heemstra PC \& JE Randall. 1993. FAO Species Catalogue, Volumen 16. Groupers of the world (family Serranidae, subfamily Epinephelinae). An annotated and illustrated catalogue of the grouper, rockcod, hind, coral grouper and lyretail species known to date. FAO Fisheries Synopsis 16(125): 1-382.

Hernández-Oldade L. 2008. Ecología reproductiva de peces de arrecifes rocosos en el sureste del Golfo de California. Tesis de Doctorado, Centro Interdisciplinario de Ciencias Marinas, Instituto Politécnico Nacional, La Paz, 184 pp.

Hyder M. 1969. Histological studies on the testis of Tilapia leucosticte y other species of the genus Tilapia (Pisces: Teleostei). Transactions of the American Microscopical Society 88: 211-231.

Lillie RD \& HM Fullmer. 1976. Histopathologic technic and practical histochemistry, 942 pp. McGraw-Hill, New York.

Lluch-Cota SE, EA Aragón-Noriega, F Arreguín-Sánchez, D Aurioles-Gamboa, JJ Bautista-Romero, RC Brusca, R Cervantes-Duarte, R Cortés-Altamirano, P Del- MonteLuna, A Esquivel-Herrera, G Fernández, ME Hendrickx, S Hernández-Vázquez, H Herrera-Cervantes, M Kahru, M Lavín, D Lluch-Belda, DB Lluch-Cota, J LópezMartínez, SG Marinote, MO Nevárez-Martínez, S Ortega-García, E Palacios-Castro, A Parés-Sierra, G Ponce-Díaz, M Ramírez-Rodríguez, CA Salinas-Zavala, RA Schwartzlose \& AP Sierra-Beltrán. 2007. The Gulf of California: review of ecosystem status and sustainability challenges. Progress in Oceanography 73: 1-26.

Lucano-Ramírez G, S Ruiz-Ramírez, B Aguilar-Palomino \& JA Rojo-Vázquez. 2001a. Listado de las especies de peces de la región costera de Jalisco y Colima, México. Ciencia y Mar 5(15): 13-20.

Lucano-Ramírez G, M Villagrán-Santa, S Ruiz-Ramírez \& MT López-Trujillo. 2001b. Histología de los ovocitos de Lutjanus peru (Nichols y Murphy, 1922) (Pisces: Lutjanidae). Ciencias Marinas 27: 335-349.

Lucano-Ramírez G, M Villagrán-Santa Cruz \& S RuizRamírez. 2001c. Cambios estructurales en las gónadas de Lutjanus peru (Pisces: Lutjanidae), en la costa sur de Jalisco, México. Boletín del Centro Investigaciones Biológicas 35: 295-316.

Lucano-Ramírez G, S Ruiz-Ramírez, G González-Sansón \& BP Ceballos-Vázquez. 2014. Biología reproductiva del pargo alazán, Lutjanus argentiventris (Pisces, Lutjanidae), en el Pacífico central mexicano. Ciencias Marinas 40(1): 33-44.

Molloy PP, NB Goodwin, IM Cote, JD Reynolds \& MJG Gage. 2007. Sperm competition and sex change: a comparative analysis across fishes. Evolution 61: 640-652. 
Rhodes KL \& I Sadovy. 2002. Reproduction in the camouflage grouper (Pisces: Serranidae) in Pohnpei, Federated States of Micronesia. Bulletin of Marine Science 70(3): 851-869.

Rodríguez-Ibarra LE. 1995. Ictiofauna de la región de la Bahía de Navidad, Jalisco. México, Tesis de Licenciatura, Centro Universitario de Ciencias Biológicas y Agropecuarias, Universidad de Guadalajara, Guadalajara, 82 pp.

Rojo-Vázquez JA \& M Ramírez-Rodríguez. 1997. Composición específica de la captura con redes de enmalle en Bahía de Navidad, Jalisco, México. Oceánides 12: 121-126.

Rojo-Vázquez JA, B Aguilar-Palomino, VH Galván-Piña, E Godínez-Domínguez, S Hernández-Vázquez, S RuizRamírez \& G Lucano-Ramírez. 2001. Ictiofauna de la pesquería ribereña en Bahía de Navidad, Jalisco, México, asociada al evento El Niño 1997-1998. Revista de Biología Tropical 49: 915-929.

Rojo-Vázquez JA, C Quiñonez-Velázquez, HA EchavarriaHeras, G Lucano-Ramírez, E Godínez-Domínguez, S Ruiz-Ramírez, VH Galván-Piña \& O Sosa-Nishizaki. 2008. The fish composition and variation catch from the small-scale gillnet fishery before, during and after the 1997-1998 ENSO event, central Mexican Pacific. Revista de Biología Tropical 56(1): 133-152.

Sadovy Y \& DY Shapiro. 1987. Criteria for the diagnosis of hermaphroditism in fishes. Copeia 1987: 136-156.

Sadovy Y, A Rosario \& A Román. 1994. Reproduction in an aggregating grouper, the red hind, Epinephelus guttatus. In: Balon EK, MN Bruton \& DLG Noakes (eds). Women in ichthyology: an anthology in honour of ET, Ro and Genie. Environmental Biology of Fishes 41: 269-286.
Sánchez-Cárdenas R, B Ceballos-Vázquez, M ArellanoMartínez, MC Valdez-Pineda \& RE Morán-Angulo. 2007. Reproductive aspects of Sphoeroides annulatus (Jenyns 1842) (Tetraodontiformes, Tetraodontidae) inhabiting the Mazatlán coast, Sinaloa, Mexico. Revista de Biología Marina y Oceanografía 42: 385-392.

Shapiro DY, Y Sadovy \& AM Gehee. 1993. Periodicity of sex change and reproduction in the red hind, Epinephelus guttatus, a protogynous grouper. Bulletin of Marine Science 53: 1151-1162.

Sluka R, M Chiappone, K Sullivan \& R Wright. 1997. The benefits of a marine fishery reserve for Nassau grouper Epinephelus striatus in the central Bahamas. Proceedings 8th International Coral Reef Symposium 2: 1961-1964.

Tuz-Sulub A, K Cervera-Cervera, JC Espinosa-Méndez \& T Brulé. 2006. Primeras descripciones de la agregación de desove del mero colorado, Epinephelus guttatus, en el Parque Marino Nacional "Arrecife Alacranes" de la plataforma Yucateca. Proceedings of the Gulf and Caribbean Fisheries Institute 57: 475-486.

West G. 1990. Methods of assessing ovarian development in fishes: a review. Australian Journal of Marine and Freshwater Research 41: 199-222.

Wolke RE, RA Murchelano, CD Dickstein \& CJ George. 1985. Preliminary evaluation of the use of macrophage aggregates (MA) as fish health monitors. Bulletin of Environmental Contamination and Toxicology 35: 222-227.

Yamamoto K \& F Yamazaki. 1961. Rhythm of development in the oocyte of the gold-fish, Carassius auratus. Bulletin of the Faculty Fisheries, Hokkaido University 12: 93-114.

Zar JH. 2010. Biostatistical analysis, 944 pp. Prentice Hall, Upper Saddle River. 